AB0670

AXIAL MANIFESTATIONS IN PATIENTS WITH AXIAL SPONDYLOARTHRITIS AND PSORIATIC ARTHRITIS: ARE THEY SIMILAR?

D. Benavent ${ }^{1}$, V. Navarro-Compán ${ }^{1}$, C. Plasencia ${ }^{1}$, D. Peiteado ${ }^{1}$, A. Villalva ${ }^{1}$, A. Balsa'. ' Hospital La Paz, Idipaz, Rheumatology Unit, Madrid, Spain

Background: Spondyloarthritis $(\mathrm{SpA})$ is a group of heterogeneous diseases that includes axial SpA (axSpA), such as ankylosing spondylitis and axial non-radiographic SpA, and Psoriatic Arthritis (PsA) with peripheral and/or axial involvement (axPsA). Currently, it is not well known if the characteristics and burden of the disease in patients with axPsA are similar to that of patients with axSpA. Objectives: To compare the demographic, clinical and structural features between patients with axSpA and axPsA.

Methods: Data from an observational prospective cohort including all patients with SpA initiating biological therapy because of predominant axial manifestations from 2002-2019 in a university hospital were analyzed. AxSpA and axPsA were defined in clinical practice according to the prescribing rheumatologist, based on clinical features and complementary examinations. Demographic information, laboratory tests, disease presentation, sacroilitis according to modified New York criteria in the pelvis X-ray, disease activity indexes (ASDAS and BASDAI) and concomitant treatment before starting biological drug were collected from the electronic medical record and biologic database. In the statistical analysis, chi square or the exact Fisher's test was used for categorical and t-student or U-Mann Whitney for continuous variables, according to the distribution of the data. Then, the association between demographic and clinical features and each disease was analysed using univariable and multivariable logistic regression models.

Results: Out of 352 included patients, $287(81.5 \%)$ had axSpA, and 65 had axPsA (18.5\%). Baseline characteristics are shown in Table 1. Mean baseline ASDAS was $3.3 \pm 0.9$ and $3.1 \pm 1.0$ for axSpA and axPsA, respectively. Biological therapies initiated can be seen in Figure 1. No significant differences at baseline were observed between axSpA and axPsA for most of the characteristics including: gender, age at diagnosis, age at starting biologic, disease duration before biologic, smoking habit, CRP, disease activity, enthesitis, dactylitis, inflammatory bowel disease (IBD), patient global assessment and sulfasalazine use. However, there were differences between diseases in some relevant characteristics. AxSpA patients had less peripheral involvement ( 41.5 vs. $78.5 \%, p=0.004)$, more uveitis ( 15.3 vs. $3.1 \%, p=0.03$ ) and were more frequently $H L A-B^{\star} 27$ positive (72.3 vs $34.1 \%, p<0.001$ ), in comparison to axPsA patients. They also had better physician global assessments (PhGA) (37.4 vs $44.4, p=0.02$ ), and a higher grade of radiographic sacroilitis. AxSpA patients used less global baseline concomitant therapy $(p=0.001)$, methotrexate $(p<0.001)$ and prednisone $(p<0.01)$, whereas they used more sulfasalazine $(p=0.003)$ than axPsA patients in our cohort. After running multivariate analyses, the absence of peripheral manifestations $(O R=4.7 ; p<0.001)$ and the positivity of HLA-B27 $(O R=5.4 ; p<0.001)$ were independently associated with axSpA.

Table 1. Baseline stratified characteristics. Results are shown as absolute numbers (percentages) or mean \pm standard deviation.

\begin{tabular}{|c|c|c|c|c|}
\hline & $\begin{array}{c}\text { AxSpA \& AxPsA } \\
n=352\end{array}$ & $\begin{array}{l}\text { AxSpA } \\
n=287\end{array}$ & $\begin{array}{l}\text { axPsA } \\
n=65\end{array}$ & p-value \\
\hline Sex (male) & $223(60.6)$ & $180(62.7)$ & $43(66.2)$ & 0.7 \\
\hline \multicolumn{5}{|l|}{ Age (years): } \\
\hline At diagnosis & $35.9 \pm 13.4$ & $35.7 \pm 13.7$ & $36.9 \pm 12.1$ & \multirow[t]{2}{*}{$\begin{array}{l}0.9 \\
0.3\end{array}$} \\
\hline At biologic starting & $44.4 \pm 13.2$ & $44.1 \pm 13.4$ & $45.8 \pm 11.6$ & \\
\hline $\begin{array}{l}\text { Disease duration before } \\
\text { biologic (years) }\end{array}$ & $17.9 \pm 10.3$ & $7.9 \pm 11.3$ & $8.9 \pm 9.0$ & 0.7 \\
\hline Current smoking habit & $158(44.9)$ & $129(44.9)$ & $29(44.6)$ & 0.9 \\
\hline HLA B27 positive & $219 / 322(67.8)$ & $204 / 281(72.3)$ & $16 / 47(34.1)$ & $<0.001$ \\
\hline CRP(mg/dL) & $12.4 \pm 17.9$ & $12.6 \pm 18.9$ & $11.1 \pm 12.7$ & 0.5 \\
\hline \multicolumn{5}{|l|}{ Clinical involvement: } \\
\hline Only axial & $170(48.2)$ & $168(58.5)$ & $14(21.5)$ & \multirow{2}{*}{$<0.001$} \\
\hline Axial and peripheral & $182(51.7)$ & $119(41.5)$ & $51(78.5)$ & \\
\hline Psoriasis & $74(21.3)$ & $11(4.2)$ & $63(97)$ & $<0.001$ \\
\hline ASDAS & $3.3 \pm 0.9$ & $3.3 \pm 1.0$ & $3.1 \pm 1.0$ & 0.1 \\
\hline BASDAI $(0-10)$ & $5.9 \pm 4.2$ & $6.1 \pm 4.5$ & $5.23 \pm 2.1$ & 0.1 \\
\hline Enthesitis & $85(41.5)$ & $73(25.4)$ & $12(28.6)$ & 0.07 \\
\hline Dactylitis & $10(2.7)$ & $7(2.4)$ & $3(4.6)$ & 0.4 \\
\hline IBD & $9(2.6)$ & $8(2.8)$ & $1(1.5)$ & 0.7 \\
\hline Uveitis & $46(13.6)$ & $44(15.3)$ & $2(3.1)$ & 0.03 \\
\hline PGA (0-100) & $63.2 \pm 21.8$ & $64.1 \pm 21.5$ & $58.8 \pm 23.2$ & 0.1 \\
\hline PhGA (0-100) & $39.1 \pm 21.5$ & $37.4 \pm 13.7$ & $44.4 \pm 22.6$ & 0.02 \\
\hline $\begin{array}{l}\text { Radiographic sacroiliitis, } \\
\text { mNY criteria }\end{array}$ & $227(64.5)$ & $203(70.7)$ & $24(36.9)$ & $<0.001$ \\
\hline Concomitant therapy: & $193(52.4)$ & $145(50.5)$ & 48 (73.8) & 0.001 \\
\hline Monotherapy & & & & \\
\hline $\begin{array}{l}\text { Only MTX } \\
\text { Only SZS }\end{array}$ & $66(20.7)$ & $36(13.9)$ & $30(46.2)$ & $<0.001$ \\
\hline Only SzS & $82(25.6)$ & $73(28.2)$ & $9(13.8)$ & 0.03 \\
\hline Prednisone use & $32(9.5)$ & $20(7.7)$ & $12(20)$ & 0.004 \\
\hline
\end{tabular}

Conclusion: Despite being spondyloartrithis with many common traits, axSpA and axPsA present some differences in clinical practice. Whereas axSpA patients are more frequently HLA-B27 positive, axPsA have more peripheral involvement. These differences in clinical presentation between both diseases may contribute to variances in therapeutic management, such as increased use of baseline concomitant therapy in axPsA patients who initiate biological therapy.

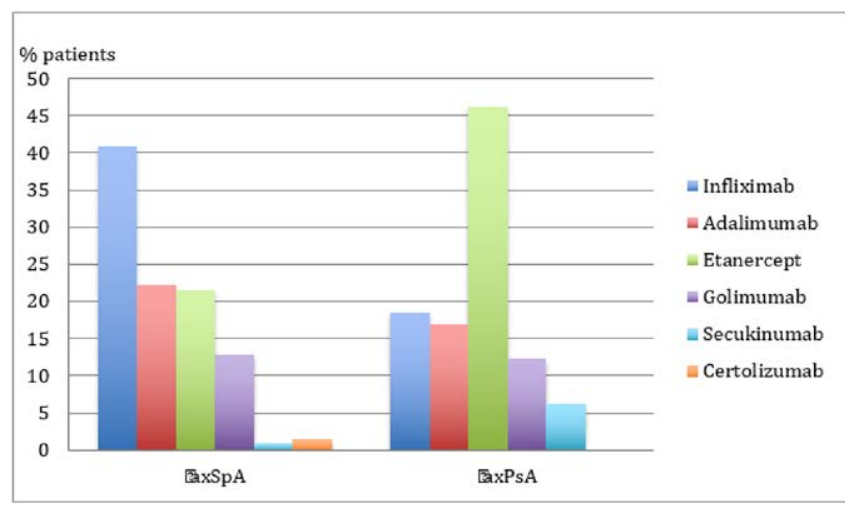

Figure 1. Biological therapies initiated in axSpA and axPsA

Disclosure of Interests: Diego Benavent: None declared, Victoria Navarro-Compán Consultant of: Abbvie, Lilly, Novartis, Pfizer, UCB, Speakers bureau: AbbVie, MSD, Lilly, Novartis, Pfizer, UCB, Chamaida Plasencia: None declared, Diana Peiteado: None declared, Alejandro Villalva: None declared, Alejandro Balsa Grant/research support from: BMS, Roche, Consultant of: AbbVie, Gilead, Lilly, Pfizer, UCB, Sanofi, Sandoz, Speakers bureau: AbbVie, Lilly, Sanofi, Novartis, Pfizer, UCB, Roche, Nordic, Sandoz DOI: 10.1136/annrheumdis-2020-eular.1703

\section{AB0671 PREVALENCE OF EXTRA-ARTICULAR MANIFESTATIONS AND IMPACT ON TARGETED DRUG PRESCRIPTION IN PATIENTS WITH SPONDYLOARTHRITIS: A RETROSPECTIVE ANALYSIS OF A REAL-LIFE COHORT}

M. Biggioggero ${ }^{1}$, E. G. Favalli ${ }^{1}$, A. Marchesoni ${ }^{1}$, R. Caporali ${ }^{1}, 2 .{ }^{1}$ Gaetano Pini-CTO Institute, Department of Rheumatology, Milan, Italy; ${ }^{2}$ Università degli Studi di Milano, Department of Clinical Sciences \& Community Health, Milan, Italy

Background: Extra-articular manifestations (EAMs), such as uveitis, inflammatory bowel diseases (IBD), and psoriasis (PSO) can frequently complicate the disease course of patients with spondyloarthritis $(\mathrm{SpA})$, although prevalence data on this regard are still controversial. The occurrence of EAMs may influence the decision to introduce a targeted therapy and also drive the choice of the most appropriate drug.

Objectives: The aim of this study is to retrospectively evaluate the prevalence of EAMs in a real-life cohort of SpA patients who were eligible to receive a targeted therapy and to investigate their impact in the choice of targeted treatment.

Methods: Clinical data of $\mathrm{SpA}$ (axial $\mathrm{SpA}[\mathrm{axSpA}]$, peripheral $\mathrm{SpA}$, and psoriatic arthritis $[\mathrm{PsA}]$ ) patients treated with a biologic or targeted synthetic Disease-Modifying Anti-Rheumatic Drug (DMARD) between December 1999 and December 2019 were extracted from a local registry. Prevalence of main SpA-related EAMs (uveitis, IBD and PSO) was calculated at the time of drug prescription, evaluating their distribution according to treatment subgroups. Comparisons between disease and treatment subgroups were made using the Fisher's test.

Results: The study included 629 patients with SpA (axSpA 26\%, peripheral SpA 24\%, PsA 50\%), 266 [42\%] women, mean age [ \pm SD] 52 [ \pm 13.2$]$ years, mean disease duration $7.8[ \pm 7.9]$ years), receiving a total of 1106 lines of targeted treatment (I-line $n=629$, II-line $n=258, \geq \mathrm{III}$-line $\mathrm{n}=219$ ) with etanercept $(\mathrm{n}=177)$, anti-TNF monoclonal antibodies (397 infliximab, 273 adalimumab, 38 certolizumab pegol, and 130 golimumab), secukinumab $(n=46)$, ustekinumab $(n=28)$, or apremilast $(n=18)$. At the time of drug introduction, $13 \%$ of $\mathrm{SpA}$ patients showed at least one EAM. The prevalence of uveitis was higher in axSpA (11.8\%) compared with both peripheral SpA $(5.5 \%, p=0.01)$ and PsA $(2.8 \%, p<0.0001)$, while IBD was more frequent in peripheral SpA $(15.6 \%)$ than in $\operatorname{axSpA}(8.1 \%, p=0.008)$ and PsA $(4.7 \% ; p<0.0001)$. The prevalence of PSO was similar in axial and peripheral SpA (8.4 versus $6.3 \%$, respectively; 
$\mathrm{p}=0.41$ ). In the overall population, the baseline presence of at least one EAM was associated with a more frequent prescription of anti-TNF monoclonal antibodies rather than etanercept $(14.4 \%$ versus $6.7 \%$, respectively; $p=0.004)$. Moreover, we observed a numerically, although not statistically significant, higher proportion of EAMs in patients treated with anti-TNF monoclonal antibodies rather than secukinumab $(6.5 \%)$, ustekinumab $(7.1 \%)$, and apremilast (5.9\%).

Conclusion: In our real-life cohort of SpA patients treated with targeted therapies, EAMs were highly represented at baseline, especially uveitis in axSpA and IBD in peripheral SpA. The presence of extra-articular involvement was associated with a preferential prescription of anti-TNF monoclonal antibodies rather than etanercept or drugs with different mechanisms of action.

References:

[1] Erol K, et al. Extra-articular manifestations and burden of disease in patients with radiographic and non-radiographic axial spondyloarthritis. Acta Reumatol Port. 2018;43(1):32-39.

[2] Molto A, Sieper J. Peripheral spondyloarthritis: Concept, diagnosis and treatment. Best Pract Res Clin Rheumatol. 2018;32(3):357-368.

[3] van der Heijde D, et al. 2016 update of the ASAS-EULAR management recommendations for axial spondyloarthritis. Ann Rheum Dis. 2017 Jun;76(6):978-991.

Disclosure of Interests: Martina Biggioggero: None declared, Ennio Giulio Favalli Consultant of: Consultant and/or speaker for BMS, Eli-Lilly, MSD, UCB, Pfizer, Sanofi-Genzyme, Novartis, and Abbvie, Speakers bureau: Consultant and/or speaker for BMS, Eli-Lilly, MSD, UCB, Pfizer, Sanofi-Genzyme, Novartis, and Abbvie, Antonio Marchesoni Speakers bureau: Abbvie, Pfizer, UCB, Novartis, Celgene, Eli Lilly, Roberto Caporali Consultant of: AbbVie; Gilead Sciences, Inc.; Lilly; Merck Sharp \& Dohme; Celgene; Bristol-Myers Squibb; Pfizer; UCB, Speakers bureau: Abbvie; Bristol-Myers Squibb; Celgene; Lilly; Gilead Sciences, Inc; MSD; Pfizer; Roche; UCB

DOI: 10.1136/annrheumdis-2020-eular.2472

\begin{tabular}{|l|l|}
\hline AB0672 & PATIENT CHARACTERISTICS AND DISEASE \\
& ACTIVITY, BUT NOT THE CRANIOCERVICAL \\
& POSTURE ABNORMALITIES PREDICT \\
& TEMPOROMANDIBULAR DISORDERS IN \\
& ANKYLOSING SPONDYLITIS PATIENTS: A CROSS- \\
& SECTIONAL, OBSERVATIONAL STUDY
\end{tabular}

E. Bilgin ${ }^{1}$, E. Bilgin ${ }^{2}$, O. Özdemir ${ }^{3}$, U. Kalyoncu ${ }^{2}{ }^{1}$ Gaziler Fizik Ted. ve Reh. Eğt. Arşt.Hastanesi, Ankara, Turkey; ${ }^{2}$ Hacettepe Üniversitesi Tıp Fakültesi, Internal Medicine, Division of Rheumatology, Ankara, Turkey; ${ }^{3}$ Hacettepe Üniversitesi Tıp Fakültesi, Physical Medicine and Rehabilitation, Ankara, Turkey

Background: There are contradictory results in the relevant literature about the relationship between objective determinants of craniocervical posture and temporomandibular disorder (TMD), whereas no study has worked on AS and TMD relationship.

Objectives: To evaluate the predictors of TMD in AS patients and its relationship with craniocervical posture, we conducted this study

Methods: AS patients aged between 18-50 years and consecutively admitted to our outpatient clinics were recruited. TMD was diagnosed by 'Diagnostic Criteria for Temporomandibular Disorders (DC/TMD)' criteria. Spinal mobility was assessed by BASMI; disease activity by ASDAS-CRP and neck disability by Neck Disability Index. We measured the craniocervical angle, cervical curvature angle, suboccipital distance, atlas-axis distance, anterior translation distance by using the lateral cervical X-rays (Figure).

Results: A total of 98 (58.2\% female) patients with a mean age of $37.4 \pm 48.2$ years was recruited (Table 1). TMD was diagnosed in $58(59,2 \%)$ patients. Spinal mobility and craniocervical posture measurements were similar among the two groups (Table2). Smoking, bruxism (in females), neck disability and AS activity (in males) were higher in TMD patients (Table 1). Multivariate analysis revealed active smoking (aOR 6.86; Cl: 1.83-25.60; $\mathrm{p}=0.004$ ), bruxism in females (aOR 17.87; Cl: 2.0-159.20; $\mathrm{p}=0.01$ ), high ASDAS in males (aOR 11.82; Cl: 1.14-122.5; $\mathrm{p}=0.038$ ) and neck disability (aOR 12.67; $\mathrm{Cl}: 3.75-42.85 ; \mathrm{p}<0.001$ ) as independent risk factors for TMD in AS patients.

Conclusion: No relationship between the craniocervical posture measurements and TMD was found in AS patients. Active smoking, high disease activity in males, bruxism in females and neck disability were found as predictors of TMD in AS patients.
Table 1. The clinical and demographical data of the study population

\begin{tabular}{lcccc}
\hline Parameter & All patients & $\begin{array}{c}\text { TMD (+) } \\
(\mathbf{n}=\mathbf{5 8})\end{array}$ & $\begin{array}{c}\text { TMD (-) } \\
(\mathbf{n}=\mathbf{4 0})\end{array}$ & $\begin{array}{c}\mathbf{P} \\
\text { value }\end{array}$ \\
\hline Gender (Female) & $57(58.2)$ & $38(65.5)$ & $19(47.5)$ & 0.076 \\
Age & $37.4 \pm 8.2$ & $37.8 \pm 7.7$ & $36.9 \pm 8.9$ & 0.57 \\
Smoking & & & & \\
$\quad$ Smoker & $33(33.7)$ & $25(43.1)$ & $8(20.0)$ & $\mathbf{0 . 0 1 7}$ \\
$\quad$ Non-smoker & $65(66.3)$ & $33(56.9)$ & $32(80.0)$ & \\
AS disease duration (year) & $8.1 \pm 5.7$ & $7.8 \pm 6.2$ & $8.6 \pm 5.0$ & 0.47 \\
AS treatment & & & & \\
$\quad$ NSAID & & & & 0.52 \\
$\quad$ Regular & $13(13.2)$ & $8(13.8)$ & $5(12.5)$ & \\
$\quad$ On-demand & $49(50.0)$ & $31(53.4)$ & $18(45.0)$ & \\
$\quad$ Sulphasalazine & $38(38.7)$ & $24(41.4)$ & $14(35.0)$ & 0.67 \\
$\quad$ Anti-TNF agents & $59(60.0)$ & $33(56.9)$ & $26(65.0)$ & 0.42 \\
Bruxism & & & & \\
Present & $61(62.2)$ & $43(74.1)$ & $18(45.0)$ & $\mathbf{0 . 0 0 3}$ \\
$\quad$ Nighttime & $18(29.5)$ & $11(25.6)$ & $7(38.9)$ & \\
$\quad$ Daytime & $15(24.6)$ & $10(23.3)$ & $5(27.8)$ & \\
$\quad$ Whole day & $28(45.9)$ & $22(51.2)$ & $6(33.3)$ & \\
$\quad$ Absent & $37(37.8)$ & $15(25.9)$ & $22(55.0)$ & \\
\hline
\end{tabular}

Table 2. Comparison of AS-related and craniocervical posture measurements

\begin{tabular}{|c|c|c|c|c|}
\hline Parameter & All patients & $\begin{array}{l}\text { TMD (+) } \\
\quad(n=58)\end{array}$ & $\begin{array}{l}\text { TMD (-) } \\
\quad(n=40)\end{array}$ & $P$ value \\
\hline \multicolumn{5}{|l|}{ AS-related measurements } \\
\hline ASDAS & $2.4 \pm 0.95$ & $2.7 \pm 0.93$ & $2.0 \pm 0.85$ & 0.001 \\
\hline Male & $2.3 \pm 1.3$ & $2.7 \pm 1.14$ & $1.7 \pm 0.85$ & 0.007 \\
\hline Female & $2.5 \pm 0.9$ & $2.7 \pm 0.82$ & $2.4 \pm 0.78$ & 0.11 \\
\hline Tragus-wall distance $(\mathrm{cm})$ & $11.7 \pm 2.55$ & $11.6 \pm 1.97$ & $12.0 \pm 3.24$ & 0.41 \\
\hline Cervical rotation (angle) & $71.6 \pm 12.78$ & $71.6 \pm 12.32$ & $71.5 \pm 13.59$ & 0.94 \\
\hline Chin-thorax distance $(\mathrm{cm})$ & $2.1 \pm 1.64$ & $2.1 \pm 1.44$ & $2.1 \pm 1.91$ & 0.90 \\
\hline BASMI & $2.0 \pm 1.19$ & $2.0 \pm 1.11$ & $2.1 \pm 1.31$ & 0.76 \\
\hline mSASSS & $3.5 \pm 4.84$ & $3.4 \pm 3.88$ & $3.8 \pm 6.03$ & 0.70 \\
\hline \multicolumn{5}{|c|}{ Measurements of craniocervical posture } \\
\hline Craniovercival angle & $79.6 \pm 10.31$ & $78.9 \pm 10.47$ & $80.6 \pm 10.11$ & 0.41 \\
\hline Cervical curvature angle & $165.4 \pm 12.42$ & $165.6 \pm 12.89$ & $165.0 \pm 11.84$ & 0.82 \\
\hline Suboccipital distance (mm) & $6.3 \pm 3.97$ & $6.2 \pm 4.04$ & $6.5 \pm 3.91$ & 0.71 \\
\hline Atlas-axis distance $(\mathrm{mm})$ & $5.2 \pm 2.43$ & $5.3 \pm 2.47$ & $5.0 \pm 2.40$ & 0.62 \\
\hline Anterior translation distance $(\mathrm{mm})$ & $10.9 \pm 13.74$ & $11.4 \pm 11.79$ & $10.1 \pm 16.35$ & 0.66 \\
\hline
\end{tabular}

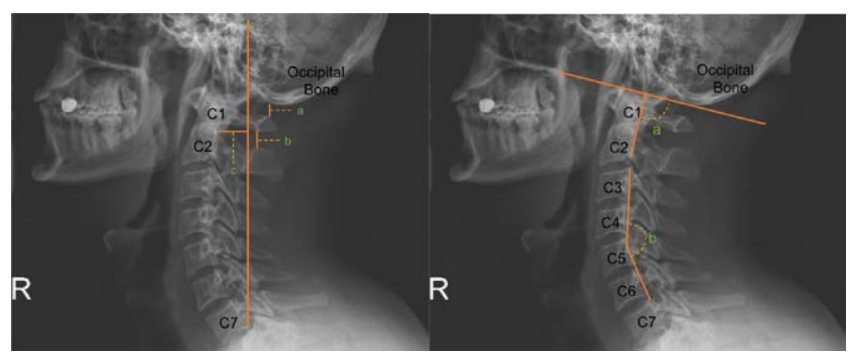

Figure. For the assessment of cranicervical posture; suboccipital distance (A.a.), atlanto-axial distance (A.b.) anterior translation distance (A.C), craniocervical angle (B.a), cervical curvature angle (B.b) were measured on standardized lateral X-rays.

Disclosure of Interests: Esra Bilgin: None declared, Emre Bilgin: None declared, Oya Özdemir: None declared, Umut Kalyoncu Consultant of: Abbvie, Amgen, Janssen, Lilly, Novartis, UCB

DOI: 10.1136/annrheumdis-2020-eular.516

\section{AB0673 $\quad$ SHINING LIGHT ON AXIAL SPONDYLOARTHRITIS: DISEASE ACTIVITY AND VITAMIN D. WHAT'S THE LINK?}

G. A. Brown ${ }^{1}$, K. M. Torsney ${ }^{2}$, E. Nikiphorou ${ }^{3} .{ }^{1}$ North West Anglia NHS Foundation Trust, Peterborough City Hospital, Rheumatology, Peterborough, 